\title{
Mapping of traditional potato fries (slap chips) from eleven potato cultivars
}

\begin{abstract}
"Slap chips" are a traditionally South Africa product that is widely consumed throughout the country. These chips are similar to French fries but are thicker and fried for a longer time at a lower temperature using a double fry method. It is assumed that different textural properties of potatoes will lead to certain cultivars being better suited for deep fat frying than others.

As part of this study, a market investigation was conducted to better understand slap chip preparation methods so as to develop a repeatable slap chip preparation method that simulates market conditions. Chips prepared using this method were evaluated by a trained sensory panel to determine sensory attributes of aroma, appearance, flavour, texture and aftertaste.

A standardised cooking method for slap chips preparation was developed. Statistical analyses showed that waxy and oily attributes grouped cultivars together, while dry matter, fried chip and earthy flavours differentiated between chips from different cultivars. No obvious grouping for cultivars within the same class according to the current South African potato classification system was found. It can be concluded that deep fat frying has such a significant impact on the chip characteristics that cultivar specific attributes have a lesser impact on the final characteristics of the product. However certain attributes such as dry matter can have an impact on the oil absorption of tubers.
\end{abstract}

Keywords: potatoes, Solanum tuberosum, slap chips, fries, cultivars, sensory panel, frying, cooking
Volume 6 Issue 3 - 2017

\author{
Muller C, Scönfeldt HC, Hall N, Pretorius B \\ Department of Animal and Wildlife Sciences, University of \\ Pretoria, South Africa
}

Correspondence: Carmen Muller, Department of Animal and Wildlife Sciences, Institute of Food, Nutrition and Well-being, University of Pretoria, Lynnwood Road, Pretoria, Gauteng, South Africa, Tel +27731551095, Fax 0865166377,

Email carmen.vanniekerk@up.ac.za, u29293295@tuks.co.za

Received: November 02, 2016 | Published: May 04, 2017

\section{Introduction}

In South Africa, $17 \%$ of potatoes produced by farmers are used by the formal processing industry. This number excludes the fresh potatoes that are purchased and subsequently processed by street vendors, corner cafés and take-away outlets. It is estimated that more than $50 \%$ of potatoes produced in South Africa are consumed by the informal market, a large consumer market which comprises $46 \%$ of the South African population., ${ }^{1,2}$

Potatoes are regarded as a bio diverse crop because various cultivars are grown and are readily available on the market. All potatoes do not deliver a uniform end (cooked/prepared) product due to species differences (dry matter), agronomical conditions (irrigation or dry land), storage and season planted and inherent textural differences due to variations between cultivars. ${ }^{3}$ This necessitates a classification system to categories potato cultivars according to their eating quality and thus enables communication and enhances satisfaction from farm to fork.

The current South African potato classification system was implemented in 2008. The system classifies different potato cultivars according to their ideal cooking categories, i.e. boil, roast, chipping (oven bake), microwave, mash and shape retention when boiled. No category for slap chips has been included in the current classification system. ${ }^{4}$ A need was therefore identified to include slap chips, as a culturally popular cooking method for potatoes, in this classification system. ${ }^{1}$

\section{South African slap chips}

Slap chips are widely consumed in South Africa and are most commonly sold by street vendors and at corner cafés and take-away outlets, which is generally considered as the informal market. ${ }^{5}$ Slap chips are different to French fries as they are thicker, have a softer exterior, creamy interior and are "slap" or bendable once cooked. They are fried at a lower temperature for a longer time, which can lead to an oilier end product with an oily mouth feel. ${ }^{6}$ Slap chips measurements range from a thickness of $1 \mathrm{~cm} \times 1 \mathrm{~cm}$ or slightly thicker and have an average length of $7 \mathrm{~cm}^{7,8}$ and are fried at temperatures ranging between $110^{\circ} \mathrm{C}$ and $160^{\circ} \mathrm{C}$. French fries are thinner with an average thickness of $0.6 \times 0.6 \mathrm{~cm}$ and an average length of $4-5 \mathrm{~cm}$. French fries are fried at a temperature of $180 \pm 5^{\circ} \mathrm{C}$ for $4.0 \pm 0.3 \mathrm{~min} .^{9}$

The global consumption of fried food is rapidly increasing; with ried potatoes being one of the most frequently consumed products. ${ }^{10}$ According to the European Union's report on potato production "the significant increase in the consumption of processed potato products has grown mainly because of the corresponding increase in fries' demand". ${ }^{11}$ Different generations have different food preferences which lead to such increased consumption Figure 1. Individuals currently entering the consumer market have a higher preference for fried and processed foods. ${ }^{12}$ Consumers also have an increased preference for certain types of potato cultivars. As indicated in Table 1 different potato cultivars have different sensory and cooking characteristics, which have an effect on the cooked product. ${ }^{13}$ 
Table I Description of the II potato cultivars identified for sampling'

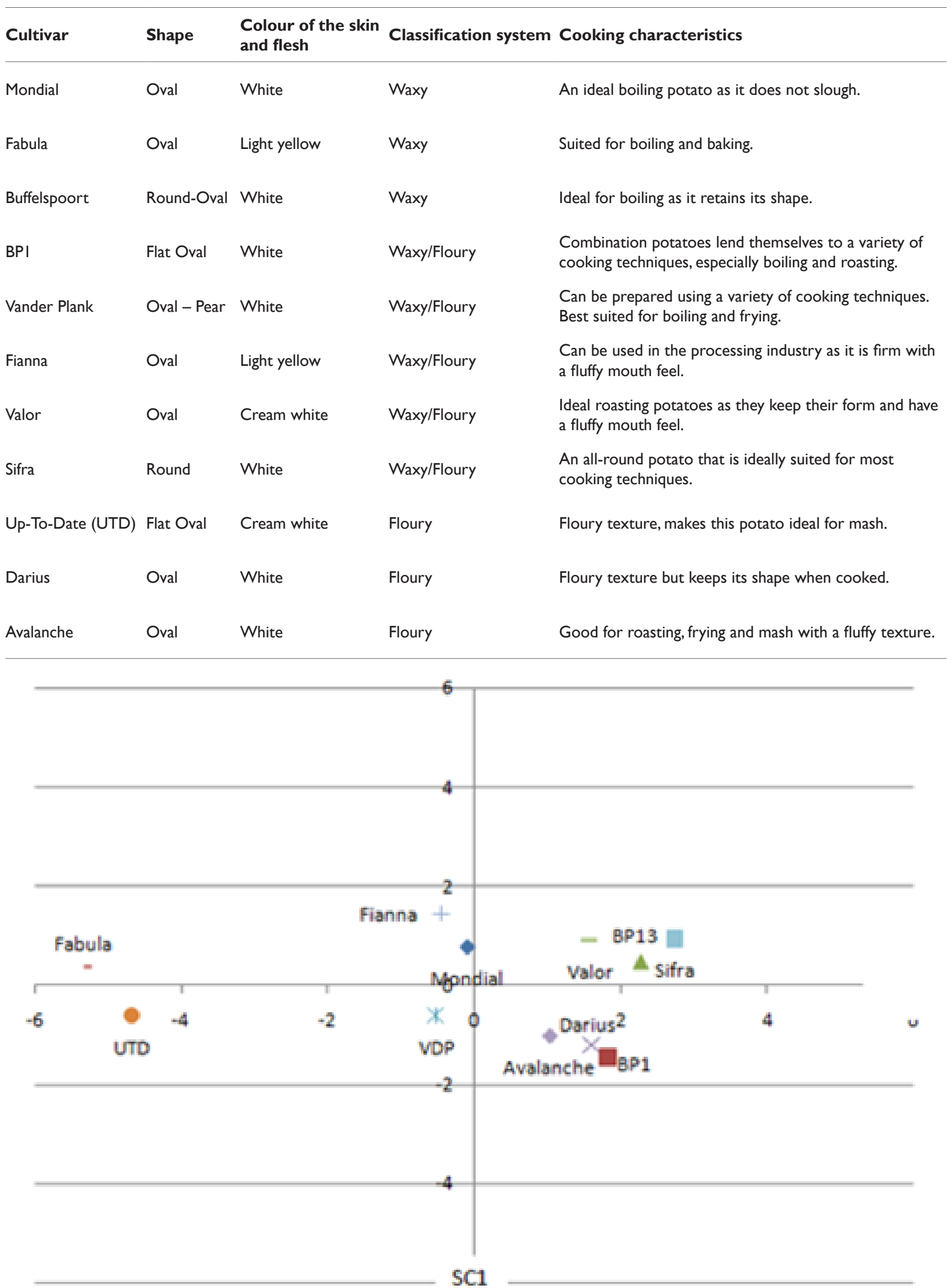

Figure I A Partial Least Squares (PLS) graph depicting the grouping of eleven different potato cultivars on the basis of a sensory panel and objective evaluation $(\mathrm{SCl}=83.71 \% ; \mathrm{SC} 2=\mid \mathrm{I} .70 \%)$. 


\section{Objectives of the study}

This study was conducted in an attempt to classify slap chips made from the 11 different types of cultivars most commonly consumed in South Africa. The purpose of the study was to determine whether certain sub-species of potatoes are better suited for making slap chips than others, considering their unique textural properties. As there is very little to no data available on slap chip preparation, there is no scientifically confirmed guideline available on the preparation methodology for the cooking of slap chips.

Therefore, the first objective of the study, namely to identify a standardised methodology to prepare slap chips was researched, a pilot study was carried out and standardised. Once the methodology had been developed and standardised, a trained descriptive sensory panel was used to extrapolate the second objective of the study, namely to describe the slap chip qualities of eleven South African potato cultivars.

\section{Developing a standardized cooking method for slap chips}

\section{Methodology}

When preparing slap chips, similar to most other foods, there are a wide variety of factors that have an influence on the final consumed product (i.e. species, cultivation, etc.). The most commonly consumed cultivars in the South African market were identified for this study to obtain a representative sample of all the different textural classes found in potatoes as shown in Table 1. Different preparation practises are also used all over the world to prepare chips, thus deeming it necessary to develop a standardised method to evaluate slap chips in the South African context.

\section{Market investigation}

To ensure that the study was true to market conditions a pilot study was conducted to understand the requirements of this market. A variety of vendors of slap chips were visited in three different areas across South Africa; rural (Limpopo), peri-urban (Vaal Triangle) and urban (Pretoria) and questioned on the methods they use to prepare slap chips, particularly in regard to cooking techniques used.

The pilot study found that vendors purchase $10 \mathrm{~kg}$ bags of fresh potatoes, mostly those available at the lowest price (the most affordable cultivar at the time was Mondial). Potatoes were peeled with hand peelers and immersed in water until they were chipped, a mainly manual process. When all the potatoes required for that day had been chipped, they were removed from the water and placed on a towel to drain off excess water. The air dried chips were fired in either a pot or a metal drum at a low temperature, between $90^{\circ} \mathrm{C}-140^{\circ} \mathrm{C}$, for the first fry using sunflower oil. The cooking process lasted between 10-30minutes. A temperature drop occurs when the raw chips are placed in the oil which leads to a longer cooking time because the oil has to be reheated. It was consequently difficult to estimate the exact temperature and time used by vendors, as they prepared different batch sizes and used different amounts of oil.

After the first frying the chips are removed from the oil and placed on a cloth or paper towel to drain off excess oil. These chips are then ready for the second fry. The second round of frying occurs when the consumer purchases the chips. The chips are fried in smaller batches at temperatures between $100^{\circ} \mathrm{C}-140^{\circ} \mathrm{C}$ and immediately served to the customer.

\section{Final frying method}

From the market investigation a standardised frying method was developed to ensure that the chips in the study were as similar as possible to the ones found in the informal market. A double fry method was used to prepare the slap chips. The potatoes were peeled and sliced into batons, with an average size of $1 \mathrm{~cm} \mathrm{x} 1 \mathrm{~cm}$ and average length of $6 \mathrm{~cm}$, and dipped into a $2.5 \%(\mathrm{v} / \mathrm{v})$ sulphur dioxide mixture to prevent browning. The raw chips were dried on a cloth and then placed in hot sunflower oil, heated to $120^{\circ} \mathrm{C}$ for 5minutes, removed from the oil and allowed to cool on a cloth to room temperature. Once the chips reached room temperature they were fried for a second time at $120^{\circ} \mathrm{C}$ for 3 minutes and served immediately.

\section{Mapping potato cultivars for slap chips}

\section{Methodology}

\section{Sampling}

The potatoes used in this study were planted in the Reitz area in the Eastern Free State, South Africa, which is one of the most productive dry land potato production areas in the country. The potatoes from the different cultivars were supplied by Potatoes South Africa, planted on the same day under dry land conditions in the same field during the summer of 2012/2013. The tubers were harvested on the 11th of April 2013. The tubers were not washed, but packed straight out of the soil into cultivar specific bags and transported to the Agricultural Research Council (ARC) Irene, Pretoria within 24hours of harvest. Tubers were placed into pre-marked boxes in a dark room at room temperature $\left(20^{\circ} \mathrm{C}\right)$ until the slap chips were prepared. The textural properties of the chosen cultivars are shown in Table 1.

\section{Sample preparation}

The slap chip samples were prepared according to the standardised developed methodology. Each day 5-7 tubers of each cultivar were washed, dried and weighed. The tubers were peeled, chipped and placed in a bucket containing a $2.5 \%(\mathrm{v} / \mathrm{v})$ sulphur dioxide and water mixture. Chips were cut into $1 \mathrm{~cm} \times 1 \mathrm{~cm}$ batons lengthwise with an average length of $6 \mathrm{~cm}$. The chips were allowed to stand in the sulphur dioxide mixture for 30 minutes, to reduce browning. After 30 minutes the chips were washed under running tap water for 10 seconds to remove excess sulphur dioxide and allowed to drip dry. The six centre chips were pre-fried in a Delonghi Roto Fryer in the preheated frying oil at $130^{\circ} \mathrm{C}$ to ensure that when the chips were lowered into the oil, the temperature dropped to the desired $120^{\circ} \mathrm{C}$ to be fried for 5 minutes. The Delonghi Roto Fryer ensures that the basket containing the chips is submerged in oil and turned constantly to achieve even frying. The oil was kept at the same temperature throughout the fryer. Excella sunflower oil was used to fry the chips, as it is the oil that vendors in the pilot study had identified as the oil they most frequently use.

Oil temperature was constantly measured using a hand held digital stainless steel probe, equipped with a J-type thermocouple. The lid of the fryer was not used to imitate market conditions and to allow constant temperature measurement. After 5 minutes of frying the chips were removed from the oil and placed on paper towel to absorb excess oil. After cooking the chips had an internal temperature of $84^{\circ} \mathrm{C}$.

The pre-fried chips were allowed to cool down to a room temperature of $23^{\circ} \mathrm{C}$ to mimic market conditions. For the second fry the same procedure was followed as for the pre-frying process but 
the chips were only fried for 3 minutes and as they were removed from the fryer, the excess oil was removed by shaking the basket. The chips were placed on paper towel to absorb excess oil. Subsequently the chips were wrapped in $10 \mathrm{~cm} \times 15 \mathrm{~cm}$ aluminium foil envelopes to ensure that they retained their heat. This also allows them to steam to simulate market conditions. The aluminium foil envelopes were each pre-coded with a randomized three digit code. These envelopes of chips were placed in an $115^{\circ} \mathrm{C}$ pre-heated oven on a baking sheet. After 5minutes the chips were removed from the oven and served to the panel on a pre-heated plate that had been warmed in a preheated oven at $60^{\circ} \mathrm{C}$.

Samples were provided to the panellists through individual cubicle doors. In addition to the aluminium foil envelope of chips the panel received an evaluation form, a pencil, an eraser and a serviette. Water was also provided, carrot slices (used as palate cleansers) and a lexicon that was already in the tasting booth. Starting at 9 o'clock in the morning the panel tasted 11 samples during 4 sessions every day over 4 days. The first, second and third session each included three tasting samples and the final session of each day included two samples. The samples were served to the panel at 10 minute intervals with a 15 minute break between sessions.

\section{Test facilities}

All samples were evaluated according to the methods described in the Annual Book of ASTM Standards. The sensory analysis facilities are equipped with all the elements necessary for an efficient sensory programme and are constructed according to ASTM design guidelines for sensory facilities.

Panellists evaluated products one at a time (four sessions per day) in separate tasting booths to reduce distraction and panellist interaction, and to ensure uninterrupted, unbiased, individual responses. After completion each panellist's score sheet was collected individually and the data was captured directly from the score sheets onto an Excel Worksheet.

The full chip was evaluated under white light conditions. White light conditions are used to ensure that the product has a natural appearance.

\section{Sensory evaluation}

Twelve experienced panellists were selected to participate in this study. These panellists were all previously trained at the Sensory Unit of the Agricultural Research Council at Irene. Panellists were chosen based on their taste and smell acuity, interest, ability to discriminate between the five basic tastes (sweet, sour, salt, bitter and umami), and availability for the entire study. The panellists have been involved in numerous sensory evaluations on food products such as meat and meat products, fats and oils, dairy products, potatoes, beverages and many more.

Before the tasting the panellists for this study participated in a general training programme consisting of four sessions to:

i. Develop appropriate descriptive terminology for the slap chips which could be used in the Lexicon

ii. Train, familiarize and test panellists for use of the evaluation scales that had been constructed and

iii. Develop and finalise the rating scales and terminology to be used.

During the training, the panellists were exposed to different potato cultivars and asked to analyse them and develop descriptive sensory terms which were used in the final evaluation Lexicon (Table 2). The lexicon of Thybo and Martens was used as a point of reference and adapted to include the attribute descriptors proposed by the panel members. ${ }^{14}$ These descriptive words included aroma, non-oral texture, oral texture, and flavour and aftertaste characteristics of the slap chips samples. A category rating scale, with one (1) denoting the least favourable condition (none: e.g. no clean/fresh oil aroma) and eight (8) denoting the most favourable condition (e.g. extremely intense clean/fresh oil aroma) was constructed (Annexure 1) and used to evaluate the different samples. To ensure that panellists were not influenced in any way, no detailed information with regard to the purpose of the project was provided.

Table 2 Lexicon developed by panel members for descriptive sensory analysis of slap chips made from eleven different potato cultivars

\begin{tabular}{|c|c|}
\hline Attribute & Description \\
\hline Aroma & $\begin{array}{l}\text { Evaluate under white light condition } \\
\text { Whole Chip to be Evaluate }\end{array}$ \\
\hline Typical fresh fried chip & Aromatic notes associated with fresh fried chips \\
\hline Potato/Earthy & Aromatic notes associated with damp soil, slightly undercooked potatoes \\
\hline Oily & Aromatic notes associated with fresh oil \\
\hline Appearance & $\begin{array}{l}\text { Initial Impression of Appearance: Only Look at the Surface and Evaluate the Oily } \\
\text { Appearance of the Chip }\end{array}$ \\
\hline Oiliness & Appearance of the outside surface of the chip. Is it oily or dry? \\
\hline $\begin{array}{l}\text { Ease of Breaking- Bending the chip till } \\
\text { two ends meet) } \\
\text { (Softness - how easily the } \\
\text { Potato Breaks) }\end{array}$ & $\begin{array}{l}\text { Force required dividing the potato into two parts by bending the two ends together. Degree of } \\
\text { bending before the potato is separated into } 2 \text { parts. } \\
\text { Breaks easily, high ease to break }(5-8) \\
\text { Elastic, makes a loop before it breaks (if at all)=low ease to break (I-5) }\end{array}$ \\
\hline
\end{tabular}


Table continued...

Attribute Description

\section{Texture}

Oiliness

Mealiness/ Floury

Waxy

Graininess (Particles)

Coarse Texture

\section{Flavour}

Typical fried chip

Earthy / Potato Skin

Bitter (Green Potato Note)

After Taste

Typical fried chip

Earthy / Potato skin

Bitter (Green potato note)
Only Evaluate the Inside of the Chip for Texture

Oiliness inside the chip. Is it oily or dry?

Expresses how floury/crumbly or dry the potato feels in the mouth after chewing. A floury potato has a Coarse overall Texture

A waxy potato has been described as moist, mushy and smooth and sometimes has glassy lumps. Is associated to some degree with stickiness. It has a smooth, waxy feeling on the palate after pressing potato with tongue.

A waxy potato has a smooth overall texture with some glassy lumps in between

Expresses the content of grainy particles in the mouth after chewing. Press potatoes against palate with tongue, large grainy pieces / particles are felt. The texture is uneven. The smoothness or coarseness of the texture. A texture can be even, but coarse or grainy, or it is smooth and fine. Evaluate the degree of coarseness or smoothness of the potato.

\section{Evaluate the whole chip}

A taste associated with typical fried potato chips

Taste associated with earthy potato skin notes

Taste on tongue stimulated by substance such as flavours associated with green/unripe potato, astringent, burned

\section{Evaluate the Whole Chip}

An aftertaste associated with typical fried potato chips

Aftertaste associated with earthy potato skin notes

Aftertaste on tongue stimulated by substance such as aftertaste associated with green/unripe potato, astringent, burned

Table 3 Least squares mean values (Standard Error of Means (SEM)) as well as the F probability (p-value)) for sensory analysis on II potato cultivars

\begin{tabular}{|c|c|c|c|c|c|c|c|c|c|c|c|c|c|}
\hline \multirow[t]{2}{*}{ Attribute } & \multirow{2}{*}{$\begin{array}{l}P \text { - } \\
\text { value }\end{array}$} & \multirow[t]{2}{*}{ Sem } & \multicolumn{4}{|c|}{$\begin{array}{l}\text { Cultivars and } \\
\text { classification }\end{array}$} & \multirow[b]{2}{*}{5} & \multirow[b]{2}{*}{6} & \multirow[b]{2}{*}{7} & \multirow[b]{2}{*}{8} & \multirow[b]{2}{*}{9} & \multirow[b]{2}{*}{10} & \multirow[b]{2}{*}{ I I } \\
\hline & & & I & 2 & 3 & 4 & & & & & & & \\
\hline \multicolumn{14}{|l|}{ Aroma } \\
\hline $\begin{array}{l}\text { Typical } \\
\text { fresh fried } \\
\text { chip }\end{array}$ & $\mathrm{P}<0.001$ & 0.112 & $5.20^{\mathrm{a}}$ & $5.25^{\mathrm{a}}$ & $5.09^{a}$ & $4.97^{\mathrm{ab}}$ & $5.10^{\mathrm{a}}$ & $5.02^{\mathrm{ab}}$ & $4.63^{c}$ & $5.07^{\mathrm{a}}$ & $5.12^{\mathrm{a}}$ & $5.24^{\mathrm{a}}$ & $4.7 I^{b c}$ \\
\hline Earthy & 0.969 & 0.073 & 2.02 & 1.96 & 1.9 & 1.9 & 1.93 & 1.96 & 1.94 & 1.9 & 1.89 & 1.99 & 1.9 \\
\hline Oily & $\mathrm{p}<0.001$ & 0.093 & $3.47^{\mathrm{ab}}$ & $3.95^{\mathrm{a}}$ & $3.32^{\mathrm{abc}}$ & $2.93^{c}$ & $3.3 I^{\mathrm{abc}}$ & $3.38^{\mathrm{ab}}$ & $3.27^{\mathrm{bc}}$ & $3.56^{\mathrm{a}}$ & $3.08^{b c}$ & $3.4 \mathrm{I}^{\mathrm{ab}}$ & $3.38^{\mathrm{ab}}$ \\
\hline \multicolumn{14}{|c|}{ Texture : Non-Oral } \\
\hline $\begin{array}{l}\text { Oiliness } \\
\text { on the } \\
\text { surface }\end{array}$ & $\mathrm{P}<0.001$ & 0.101 & $4.29^{a}$ & $3.28^{d}$ & $3.76^{c}$ & $3.38^{\mathrm{d}}$ & $4.27^{\mathrm{a}}$ & $3.42^{\mathrm{d}}$ & $3.85^{\mathrm{bc}}$ & $4.34^{\mathrm{a}}$ & $3.7 I^{c}$ & $4.18^{a}$ & $4.0 I^{\mathrm{ab}}$ \\
\hline $\begin{array}{l}\text { Ease of } \\
\text { breaking }\end{array}$ & $\mathrm{p}<0.00 \mathrm{I}$ & 0.175 & $4.15^{\mathrm{defg}}$ & $4.34^{\text {cdef }}$ & $5.08^{\mathrm{ab}}$ & $5.47^{\mathrm{a}}$ & $4.44^{\text {cde }}$ & $4.26^{\text {cdefg }}$ & $4.58^{\mathrm{cd}}$ & $3.83^{g}$ & $3.87^{\mathrm{fg}}$ & $4.04^{\mathrm{efg}}$ & $4.65^{b c}$ \\
\hline
\end{tabular}


Table continued..

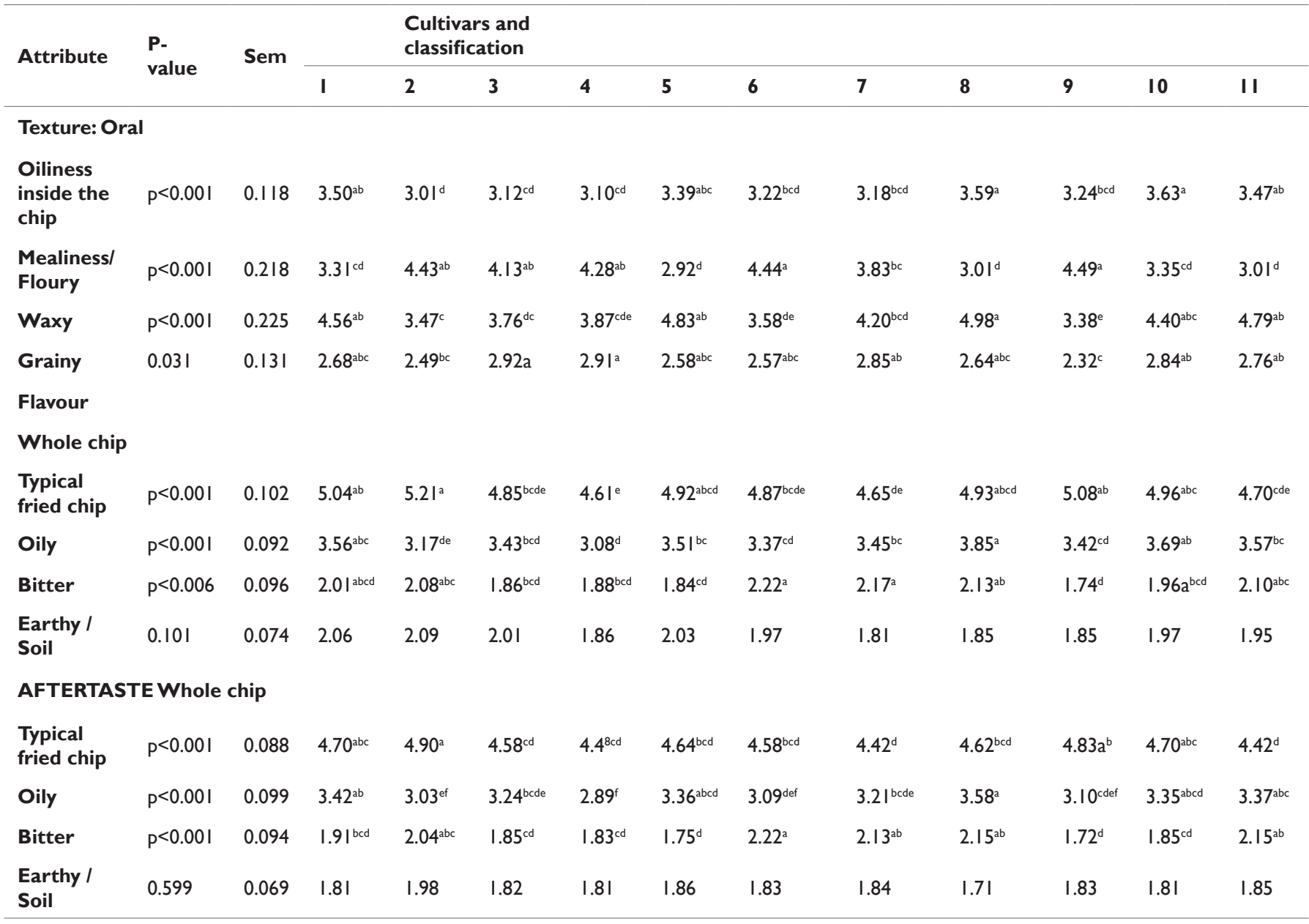

\section{Objective evaluation}

Dry matter analysis on the tubers was performed gravimetrically according to the AOAC 934.01 method. Specific gravity was determined by weighing five tubers individually as is, followed by an underwater weighing where the tuber is placed in a net and submerged in water. Specific gravity is then calculated with the following equation: ${ }^{15}$

$$
\text { Specific gravity }=\frac{\text { Weight in air }}{(\text { Weight in air-Weight under water })}
$$

\section{Statistical analyses}

The data was captured using an Excel spreadsheet. Data was inspected for outliers using a residual test.

Quantitative descriptive data of all attribute scores were subjected to analysis of variance ANOVA) using the GenStat statistical software. ${ }^{16}$ Analysis of variance was performed to determine the differences among cultivar effects at the 5\% level. The Partial Least Squares regression procedure (PLS) of GenStat was used to establish which of the set of correlated objective ( $\mathrm{X}$ matrix) variables and 11 cultivars were applied to determine and explain variation in the sensory profile (Y matrix) of slap chip potatoes.

\section{Results and discussion}

\section{Grouping of potato cultivars according to slap chip qualities}

The ANOVA analysis (Table 4) detected significant differences $(p \leq 0.05)$ for 14 of the 17 sensory attributes between the different cultivars. Significant differences were seen in scores for aroma, nonoral texture, oral texture, flavour and aftertaste attributes in chips from the eleven cultivars, except for earthy aroma, earthy flavour and earthy aftertaste. In future earthy/soil attributes can be removed from the taste panel form and need no longer be measured as an attribute. Deep fat frying of food can significantly alter the texture as well as flavour of a food. Certain textural and flavour aspects that already exist in the tubers can be enhanced and others decreased during the process of frying. ${ }^{17}$ The textural appeal of a potato has a critical influence on the acceptability of the potato and is a dominant indicator of quality among consumers. ${ }^{18}$

As there is no significant difference in the texture of the different slap chips, it can be assumed that all the cultivars would be texturally acceptable to consumers. However, no clear pattern of differences amongst the types of cultivars (waxy, waxy/floury, floury) emerged for any of the attributes, indicating that there are no significant differences in the textural properties between the different classes of tubers in the current classification system. Although there is 
no cultivar that performed significantly better than the rest, seven (Mondial, BP1, Bp13, Van Der Plank, Fabula, Valor, Avalanche) of the eleven cultivars had generally higher values for typical fried chip flavour and typical fried chip aroma. This may indicate that they may be better suited for slap chip preparation.

Table 4 Specific gravity and dry matter of analysis of eleven different potato cultivars

\begin{tabular}{|c|c|c|c|c|c|c|c|c|c|c|c|c|}
\hline \multirow{2}{*}{ Attribute } & \multirow{2}{*}{ P-value/unit } & \multicolumn{11}{|c|}{ Cultivars } \\
\hline & & I & 2 & 3 & 4 & 5 & 6 & 7 & 8 & 9 & 10 & II \\
\hline $\begin{array}{l}\text { Specific } \\
\text { gravity }\end{array}$ & $\mathrm{p}<0.00 \mathrm{I}$ & $1.06^{\mathrm{ab}}$ & $1.07^{\mathrm{bc}}$ & $1.068^{\mathrm{bc}}$ & $1.073^{b c}$ & $1.062^{\mathrm{b}}$ & $1.064^{b c}$ & $1.077^{c}$ & $1.06 I^{\mathrm{ab}}$ & $1.065^{b c}$ & $1.047^{\mathrm{a}}$ & $1.059^{\mathrm{ab}}$ \\
\hline Dry matter & $g$ & 22.2 & 20.1 & 22.4 & 26.5 & 19.3 & 20.9 & 27.3 & 22.6 & 20.4 & 19.8 & 20.4 \\
\hline
\end{tabular}

Aroma is an important aspect of fried food as the smell is associated with the textural and flavour appeal of food prepared in this manner. ${ }^{19}$ All the cultivars had a typical fried chip aroma $(\mathrm{p}<0.001)$, except for Fianna and Sifra, which had a low typical fried chip aroma and aftertaste.

When evaluated on appearance, Mondial, Fabula, VDP, Sifra and Avalanche had an oily surface $(\mathrm{p}<0.001)$, with BP1, Darius and UTD differing significantly with a low oily surface. BP13 and Darius had a high ease of breaking $(\mathrm{p}<0.001)$ and Valor a low ease of breaking.

The texture of Mondial, Fabula, VDP, Sifra and Avalanche inside the chip was higher $(\mathrm{p}<0.001)$ and BP1 lower. This corresponds to the results on oily surface appearance. BP13, BP1, Valor, UTD and Darius had a floury texture $(\mathrm{p}<0.001)$ and Mondial, Fabula, VDP, Sifra and Avalanche had a waxy texture $(\mathrm{p}<0.001)$. All the cultivars except for BP1 and Valor had a high grainy texture $(\mathrm{p}=0.031)$.

Overall oiliness (aroma, texture, flavour and aftertaste) was lowest in Darius, with few statistical differences observed between Darius and BP1, BP13, UTD and Valor. Although, dry matter (Table 4) was high for both Fianna (27.3) and Darius (26.5), it seems to have influenced oil absorption to a greater extent in Darius. Mondial, Fabula, BP1, VDP, Valor and Avalanche had a high typical fried chip flavour $(\mathrm{p}<0.001)$. Darius had a low typical fried chip flavour. Mondial, Fabula and Avalanche had a high oily $(\mathrm{p}<0.001)$ and bitter $(\mathrm{p}=0.006)$ flavour and BP1 and Darius a low oily flavour, while Valor had a low bitter flavour. Fabula, UTD, BP1, Fianna and Sifra also had a high bitter aftertaste $(\mathrm{p}<0.001)$.

Mondial, BP1, Valor and Avalanche had a typical fried chip aftertaste $(p<0.001)$, and Fianna and Sifra a low typical fried chip aftertaste. Mondial, Fabula, Sifra, Avalanche and VDP had a high oily aftertaste $(\mathrm{p}<0.001)$ and Darius a low oily aftertaste, Darius also had a low oily aroma $(\mathrm{p}<0.001)$.

Mondial and Fabula had high values for most of the attributes. Avalanche had high values for aroma and flavour attributes. Darius had low values for flavour. There was no significant difference in the earthiness of aroma, flavour and aftertaste of the chips ( $p>0.05)$.

\section{Correlations between qualities}

A single correlation matrix was drawn up to identify correlations between attributes identified by the taste panel. A correlation of 0.8 and higher indicates a significant correlation and a correlation of 0.6 and higher indicates a fair correlation..$^{20}$

Strong correlations were found between all aspects of oiliness. Oily texture correlated with oily aroma $(\mathrm{r}=0.7820)$ and highly correlated with oily appearance $(r=0.8760)$, oily flavour $(r=0.8859)$ and oily aftertaste $(r=0.8480)$. Frying potatoes for a long time at a low temperature can have a significant impact on the amount of oil absorbed. ${ }^{10}$ This preparation method causes an overall oiler end product.

Oily texture correlated positively with a waxy texture $(\mathrm{r}=0.7882)$, while it correlated negatively with a floury texture $(\mathrm{r}=-0.8201)$. This indicates that slap chips with a waxy texture appear oilier than slap chips made from potatoes with a floury texture. It has repeatedly been found that potatoes with a higher moisture and lower solids content (waxy), absorb more oil during frying because larger amounts of moisture are lost during cooking, which gives the chips an oilier appearance and taste. For this reason floury potatoes are generally preferred when preparing chips. ${ }^{6,21}$

It was found that if a potato appeared oily it had an oily flavour $(r=0.9049)$ as well as an oily aftertaste $(r=0.9423)$. A very strong negative correlation was seen between the texture of floury and waxy potatoes $(r=0.9813)$ indicating that there was a significant difference in the textural properties of the different cultivars. A study conducted on boiled potatoes indicated that floury characteristics are among the most easily evaluated sensory attributes that can be evaluated by a sensory panel potatoes..$^{22}$ In this study panellists could also identify the difference between waxy and floury slap chips.

Waxy potatoes had a strong correlation with oily aftertaste $(\mathrm{r}=0.8241)$, while floury potatoes had a negative correlation with oily aftertaste $(\mathrm{r}=-0.8241)$. A chip with an oily flavour is highly likely to have an oily aftertaste $(\mathrm{r}=0.9619)$. A consumer preference study showed that American consumers prefer chips that do not have an oily aftertaste and appearance. ${ }^{23}$ Chips that had a typical fresh potato aroma also had a typical fried chip flavour $(\mathrm{r}=0.8204)$ and typical fried aftertaste $(\mathrm{r}=0.8490)$.

Dry matter and specific gravity correlated less with each other than expected at $r=0.6831$. A study conducted in 1975 in America indicated that there was a strong correlation $(\mathrm{r}=0.912)$ between the specific gravity and dry matter content of 1269 tubers. ${ }^{20}$ In a study conducted in Pakistan, a correlation of $\mathrm{r}=0.5966$ was seen between dry matter and specific gravity. ${ }^{24}$ Significant differences are generally seen in the correlation of specific gravity and dry matter in potatoes from different countries. These differences may be due to different cultivars and agronomical methods that are used in different countries.

Specific gravity is one of the most common methods used in the potato industry to determine the cooking and chipping quality of tubers as specific gravity is a determining factor of textural properties and cooking quality. ${ }^{1}$ The specific gravity determines the total solids and dry matter of a potato tuber. ${ }^{15}$ 
Dry matter is seen as a more reliable, as it is a scientifically repeatable method of evaluation. Dry matter is measured by drying a known wet weigh of finely grated tuber, placing it in a drying oven to extract all the moisture from the flesh and then weighing it again to determine the total dry matter content. ${ }^{25}$

Because specific gravity measurements are simpler to obtain they are more often the chosen method of evaluation. Oregon State University developed a specific gravity and dry matter reference guide which indicates the relationship between specific gravity and dry matter. Specific gravity measures most commonly fall in ranges between 1.055-1.095 with correlating dry matter values of between $16.5 \%-24 \% .{ }^{26,27}$ In a study conducted in Pakistan the specific gravity of 32 different cultivars of potatoes was found to vary between 1.0343 $1.1443^{24}$ which is a wider and higher range than the average values seen in European potatoes. Once again this can be due to different cultivars and agronomical methods that are used in different countries.

Dry matter correlated with typical fried chip flavour $(\mathrm{r}=-0.6634)$ and earthy flavour $(\mathrm{r}=-0.6259)$. Specific gravity correlated with typical fried chip flavour $(-0.6634)$, earthy flavour (-0.6259), oily flavour $(-0.6675)$ and oily texture $(\mathrm{r}=0.8386)$.

Typical fresh fried chip aroma correlated with typical fried chip flavour (0.8204) and typical fried chip aftertaste (0.8490). Typical fried chip aftertaste had a strong correlation with typical fried chip flavour (0.9665).

Both specific gravity and dry matter had a low correlation with floury $(\mathrm{r}=0.5327 ; \mathrm{r}=0.1836)$ and waxy texture $(\mathrm{r}=-0.4331 ; \mathrm{r}=-0.0271)$ indicating that, in the case of slap chips, neither of these criteria can be used as a determining factor for the floury or waxy texture observed through sensory testing. A consumer preference study found that fried potatoes with a low specific gravity content and thus a waxy texture were preferred over fried potatoes with a floury texture based on their textural appeal. However floury potatoes were preferred due to their flavour. ${ }^{28}$

The first two dimensions of the PLS (SC1 and SC2) accounted for $95.41 \%$ of the data, $83.71 \%$ was declared in the first dimension and $11.70 \%$ was declared in the second dimension with latent roots of 72.66 and 10.16 (should be $>1$ to be significant).

In the first dimension ( $\mathrm{SC} 1)$ the positive loadings were typical fried chip flavour $(\mathrm{r}=0.669)$, earthy flavour $(\mathrm{r}=0.620)$; and dry matter $(r=-0.999)$, depicted as a negative loading. These attributes of the first dimension explain the different grouping of Fabula and UTD versus Sifra, BP1, BP13 and Darius.

The second dimension (SC2) variance had negative loadings for floury texture $(\mathrm{r}=-0.965)$ and positive loading for waxy texture $(\mathrm{r}=0.984)$, oily appearance $(\mathrm{r}=0.915)$, oily aftertaste $(\mathrm{r}=0.871)$, oily flavour $\left(\mathrm{r}=0.807\right.$ and oily aroma $(\mathrm{r}=0.743) .^{29}$

Waxy texture and oily appearance, oily aftertaste and oily flavour contributed to the grouping of Fianna, Mondial, Valor, Sifra and Buffelspoort (BP13), in contrast to UTD, VDP, Avalanche, Darius and BP1.

Table 5 Percentage variance explained in the first and second dimension for sensory attributes and objective tests done on slap chips made from eleven different cultivars

Table 5 Percentage variance explained in the first and second dimension for sensory attributes and objective tests done on slap chips made from eleven different cultivars

\begin{tabular}{|c|c|c|c|c|c|}
\hline \multirow{2}{*}{$\begin{array}{l}\text { Y Matrix } \\
\text { Sensory attributes }\end{array}$} & \multicolumn{2}{|c|}{ \%Variance explained } & \multirow{2}{*}{$\begin{array}{l}\text { X Matrix } \\
\text { Objective measures }\end{array}$} & \multicolumn{2}{|c|}{ \%Variance explained } \\
\hline & Ist Dimension & 2nd Dimension & & Ist Dimension & 2nd Dimension \\
\hline Typical fresh fried chip aroma & 4.17 & 5.48 & NDF & 0.81 & 2.32 \\
\hline Earthy aroma & 0.28 & 0.34 & DM & 98.8 & 6.83 \\
\hline Oily Aroma & 1.83 & 15.1 & SG & 0.16 & 0.01 \\
\hline Oiliness non-oral & 3.38 & 35.2 & & & \\
\hline Ease of breaking & 10.5 & 11.8 & & & \\
\hline Oiliness oral & 2.88 & 17.5 & & & \\
\hline Mealiness oral & 4.950 & 62.0 & & & \\
\hline Waxy oral & 1.11 & 58.3 & & & \\
\hline Grainy oral & 3.90 & 6.15 & & & \\
\hline Typical fried chip flavour & 4.74 & 5.09 & & & \\
\hline Oily flavour & 2.45 & 17.5 & & & \\
\hline Bitter flavour & 0.86 & 3.30 & & & \\
\hline Earthy flavour & 2.28 & 1.13 & & & \\
\hline
\end{tabular}




\begin{tabular}{|c|c|c|c|c|c|}
\hline \multirow{2}{*}{$\begin{array}{l}\text { Y Matrix } \\
\text { Sensory attributes }\end{array}$} & \multicolumn{2}{|c|}{ \%Variance explained } & \multirow{2}{*}{$\begin{array}{l}\text { X Matrix } \\
\text { Objective measures }\end{array}$} & \multicolumn{2}{|c|}{ \%Variance explained } \\
\hline & Ist Dimension & 2nd Dimension & & Ist Dimension & 2nd Dimension \\
\hline Typical fried chip after taste & 3.39 & 6.64 & & & \\
\hline Oily after taste & 2.35 & 17.8 & & & \\
\hline Bitter after taste & 0.97 & 2.96 & & & \\
\hline Earthy after taste & 0.64 & 3.64 & & & \\
\hline
\end{tabular}

Currently potato classification is mainly determined by measuring the specific gravity of a cultivar. Specific gravity is a relatively poor indicator $(\mathrm{r}=-0.228)$ of texture, but it appears that dry matter content can deliver more accurate results $(r=-0.999)$ for chips. ${ }^{30,31}$

The percentage variance (PLS) as explained in Table 5 shows that Annexure I

Name Day, 4 (19 April) Session, 3 dependant variables (sensory attributes) are primarily explained by oral mealiness in the second dimension while no sensory attributes explained variance in the first dimension. Variance of the independent variables, i.e. chemical analysis, was explained by percentage dry matter.

\begin{tabular}{|c|c|c|c|c|c|c|c|c|}
\hline \multirow{2}{*}{$\begin{array}{l}\text { Attribute } \\
\text { Aroma } \\
\text { Evaluate whole chip }\end{array}$} & \multicolumn{8}{|c|}{ Sample Code 104} \\
\hline & None & Hint & Slight & Weak & Moderate & High & Very High & Extremely \\
\hline Typical fresh fried chip & 1 & 2 & 3 & 4 & 5 & 6 & 7 & 8 \\
\hline Earthy (with earthy potato skin notes) & 1 & 2 & 3 & 4 & 5 & 6 & 7 & 8 \\
\hline Oily & 1 & 2 & 3 & 4 & 5 & 6 & 7 & 8 \\
\hline Texture: Non-Oral & None & Hint & Slight & Weak & Moderate & High & Very High & Extremely \\
\hline Oiliness on the surface & 1 & 2 & 3 & 4 & 5 & 6 & 7 & 8 \\
\hline Ease of breaking (bend chip till two ends join) & & 2 & 3 & 4 & 5 & 6 & 7 & 8 \\
\hline $\begin{array}{l}\text { Texture: Oral } \\
\text { Evaluate the inside of the chip only }\end{array}$ & None & Hint & Slight & Weak & Moderate & High & Very High & Extremely \\
\hline Oiliness inside the chip & I & 2 & 3 & 4 & 5 & 6 & 7 & 8 \\
\hline $\begin{array}{l}\text { Mealiness/Floury - how floury/crumbly or dry } \\
\text { the potato is }\end{array}$ & & 2 & 3 & 4 & 5 & 6 & 7 & 8 \\
\hline $\begin{array}{l}\text { Waxy: moist, mushy (smooth) with some lumps } \\
\text { and stickiness }\end{array}$ & & 2 & 3 & 4 & 5 & 6 & 7 & 8 \\
\hline $\begin{array}{l}\text { Grainy: content of grainy particles in the mouth } \\
\text { after chewing }\end{array}$ & & 2 & 3 & 4 & 5 & 6 & 7 & 8 \\
\hline $\begin{array}{l}\text { Flavour } \\
\text { Evaluate the whole chip }\end{array}$ & None & Hint & Slight & Weak & Moderate & High & Very High & Extremely \\
\hline Typical fried chip & I & 2 & 3 & 4 & 5 & 6 & 7 & 8 \\
\hline Oily & 1 & 2 & 3 & 4 & 5 & 6 & 7 & 8 \\
\hline $\begin{array}{l}\text { Bitter (caffeine) or (green/unripe potato, } \\
\text { astringent, burned) }\end{array}$ & I & 2 & 3 & 4 & 5 & 6 & 7 & 8 \\
\hline Earthy/Soil (with earthy potato skin notes) & I & 2 & 3 & 4 & 5 & 6 & 7 & 8 \\
\hline
\end{tabular}


Table continued..

\begin{tabular}{|c|c|c|c|c|c|c|c|c|}
\hline Attribute & Sampl & ode 10 & & & & & & \\
\hline $\begin{array}{l}\text { After Taste } \\
\text { Whole chip }\end{array}$ & None & Hint & Slight & Weak & Moderate & High & Very High & Extremely \\
\hline Typical fried chip & I & 2 & 3 & 4 & 5 & 6 & 7 & 8 \\
\hline Oily & I & 2 & 3 & 4 & 5 & 6 & 7 & 8 \\
\hline Bitter (green/unripe potato, astringent, burned) & 1 & 2 & 3 & 4 & 5 & 6 & 7 & 8 \\
\hline Earthy/Soil (with earthy potato skin notes) & I & 2 & 3 & 4 & 5 & 6 & 7 & 8 \\
\hline
\end{tabular}

\section{Conclusions and recommendations}

A standardised cooking method was developed to ensure that the slap chips tested in this study were true to market practices. The trained sensory panel that tested the slap chips found no obvious grouping for cultivars within the same class according to the South African potato classification system.

Oiliness was one of the biggest discriminating factors seen between cultivars. Chips that appeared oily had an oily flavour, aroma, feel and aftertaste. Darius was the cultivar that had the lowest scores for oily attributes. However, there was no clear difference amongst the types of cultivars (waxy, waxy/floury, floury) for sensory attributes, which indicates that there is no significant difference in the textural properties of the tubers when they are deep fat fried. However certain cultivars scored higher on typical slap chip attributes, these included Mondial, BP1, BP13, Van Der Plank, Fabula, Valor and Avalanche.

It can be concluded that deep fat frying has such a significant impact on the chip characteristics that cultivar specific attributes have a lesser impact on the final characteristics of the product.

It is recommended that preference for different cultivars be tested using typical consumers of slap chips.

\section{Acknowledgements}

The author would like to acknowledgement the support of the University of Pretoria Institutional Research Theme on Food, Nutrition and Well-being, as well as the Agricultural Research Council, Irene, Potatoes South Africa.

\section{Conflict of interest}

Author declares that there is no conflict of interest.

\section{References}

1. Potatoes South Africa. Industry information. Potatoes South Africa. 2014.

2. Stats SA. Statistics South Africa. 2013.

3. Van Marle JT, de Vries RV, Wilkinson EC, et al. Sensory evaluation of the texture of steam-cooked table potatoes. Potato Research. 1997;40(1):79-90

4. Schönfeldt H. Science based classification system for South African potatoes. 2011

5. Steyn NP, Labadarios D, Nel JH. Factors which influence the consumption of street foods and fast foods in South Africa-a national survey. Nutr J. 2011;10:104
6. O’Connor CJ, Fisk KJ, Smith BG, et al. Fat uptake in French fries as affected by different potato varieties and processing. Journal of Food Science. 2001;66(6):903-908.

7. http://www.tastemag.co.za/Trends-608/Pro-in-the-kitchen-chips.aspx

8. http://www.eatout.co.za/article/and-the-nominees-for-the-2013-eat-outtop-10-are/

9. Murniece I, Karklina D, Galoburda R, et al. Nutritional composition of freshly harvested and stored Latvian potato (Solanum tuberosum L.) varieties depending on traditional cooking methods. Journal of Food Composition and Analysis. 2011;24:699-710.

10. Rimac-Brncic S, Lelas V, Rade D, et al. Decreasing of oil absorption in potato strips during deep fat frying. Journal of Food Engineering. 2004;64(2):237-421.

11. Fernqvist F, Spendrup S, Ekelund L. Changing consumer intake of potato, a focus group study. British Food Journal. 2015;117(1):210-220.

12. Wansink B, Cheney MM, Chan N. Exploring comfort food preferences across age and gender. Physiol Behav. 2013;79:739-747.

13. Thybo AK, Szczypinsky PM, Karlsson AH, et al. Prediction of sensory texture quality attributes of cooked potatoes by NMR-imaging (MRI) of raw potatoes in combination. Journal of Food Engineering 2004;61:91-100.

14. Thybo AK, Martens M. Development of a sensory texture profile of cooked potatoes by multivariate data analysis. Journal of Texture Studies. 1998;29(4):453-468.

15. http://www.dpi.vic.gov.au/agriculture/horticulture/vegetables/potatoes/ potatoes-measurement-specific-gravity

16. Payne RW, Murray PA, Harding SA. Gen Stat ${ }^{\circledR}$ for Windows ${ }^{\mathrm{TM}}$ Introduction. 15th ed. Hemel Hempstead, VSN International. 2012.

17. Urbancic S, Kolar MH, Dimintrijevic D, et al. Stabilisation of sunflower oil and reduction of acrylamide formation of potato with rosemary extract during deep-fat frying. Lebensmittel-Wissenschaft + Technologie. 2014;57(2):671-678.

18. Bourne M. Food texture and viscosity: concept and measurement. 2nd ed. New York: Academic Press; 2002.

19. Ansarifar E, Shahidi F, Mohebbi M, et al. A new technique to evaluate the effect of chitosan on properties of deep-fried Kurdish cheese nuggets by TOPSIS. LWT - Food Science and Technology. 2015;62(2):1211-1219.

20. Schippers PA. The relationship between specific gravity and percentage dry matter in potato tubers. American Journal of Potato Research. 1976;53(4):111-122.

21. Gamble MH, Rice P, Selman JD. Relationship between oil uptake and moisture loss during frying of potato slices from cv. Record U.K. tubers. International Journal of Food Science and Technology. 1987;22(3):233-241. 
22. Thybo AK, Martens M. Analysis of sensory assessors in texture profiling of potatoes by multivariate modelling. Food Quality and Preference. 2000;11(4):283-288.

23. Lloyd BJ, Farkas BE, Keener KM. Quality comparison of French fry style potatoes produced by oven heating, immersion frying and controlled dynamic radiant heating. Journal of Food Processing and Preservation. 2004;28(6):460-472.

24. Abbas G, Frooq K, Hafiz IA, et al. Assessment of processing and nutritional quality of potato genotypes in Pakistan. Pak J Agri Sci. 2011;48(3):169-175.

25. Van Dijk C, Fischer M, Holm J, et al. Texture of cooked potatoes (Solanum tuberosum). 1. Relationships between dry matter content, sensory-perceived texture, and near-infrared spectroscopy. Journal of Agriculture and Food Chemistry. 2002;50(18):5082-5088.
26. http://www.dpi.vic.gov.au/agriculture/horticulture/vegetables/potatoes/ potatoes-factors-affecting-dry-matter

27. Mosley R, Chase RW. Potato Health Management. In: Selecting Cultivars and Obtaining Healthy Seed Lots. APS Press; 1993:19-27.

28. Pardo JE, Alvarruiz A, Perez JI. Physical-chemical and sensory quality evaluation of potato varieties (Solanum Tuberosum L.). Journal of Food Quality. 2000;23(2):149-160.

29. Denner F, Venter S. Handle ding vir aartappelproduksie in Suid-Afrika. 2nd ed. Pretoria: Potateos South Africa; 2011.

30. http://ec.europa.eu/agriculture/fruit-and-vegetables/product-reports/ potatoes/index_en.htm

31. http://www.potatoes.co.za/industry-information.aspx 